\title{
Research and development of a virtual instrument for measurement, analysis and monitoring of the Power Quality
}

\author{
J.Esim ${ }^{1}$, I.J. Oleagordia ${ }^{1}$ and S. Loureiro ${ }^{2}$ \\ ${ }^{1}$ Department of Electronic Technology \\ ${ }^{2}$ Department of Electrical Engineering \\ E.U.I.T.I of Bilbao, University of the Basque Country (UPV/EHU - Spain)
}

Phone/Fax number: +0034946014304 e-mail: jesim001@ikasle.ehu.es, ij.oleagordia@ehu.es, sergio.loureiro@ehu.es

\begin{abstract}
This paper is about the design of a power quality monitoring system based on LabVIEW for factory power quality defined in the IEEE Standard 1459-2010 [1] for single-phase, three phase three-wire and three-phase four-wire power systems [1] and [2]. With LabVIEW as development platform, composed by some functional modules such as data acquisition, data processing, data storage, and data report, etc. defined in International standards concerning electrical power quality Standard EN 50160 [3] and [4]. This system has advantages of better analyzed affection and low cost, and can be extended easily.
\end{abstract}

Keywords: LabView Virtual Instrument, Standard EN 50160, IEEE Standard Definitions 1459-2010, Power quality measurement, Harmonic analyzer.

\section{Introduction}

Due to the intensive use of power converters and other nonlinear loads in industry and by consumers in general, it can be observed an increasing deterioration of the power systems voltage and current waveforms, the presence of harmonics in lines, interference problems in communication systems and, sometimes, in operation failures of electronic equipments.

Because of these and other problems, the issue of the power quality delivered to the end consumers is, more than ever, an object of great concern. International standards concerning electrical power quality (EN 50160, IEEE Standard 1459-2010 among others) impose that electrical equipments and facilities should not produce harmonic contents greater than specified values, and also specify distortion limits to the supply voltage [3] and [4].

The paper is organized as follows. Section 2. describes the two International standards concerning electrical power quality related to this work. Section 3. gives the description of the hardware used Section 4. describes briefly the programming environment used for creating the measurement system: data acquisition method, the effective values of the voltage and current, fundamental wave of the three-phase voltage and current, etc. In Section 5. results of experiments. Conclusions are given in Section 6.

\section{Standard}

\section{A. Standard EN 50160.}

In standard EN 50160 several voltage parameters are defined [3] and [4]. The most important are:

Harmonic voltage a sinusoidal voltage with a frequency equal to an integer multiple of the fundamental frequency of the supply voltage. Harmonic voltages can be evaluated: individually, globally.

$T H D_{u}=\sqrt{\frac{\sum_{h=2}^{40}\left(U_{h}\right)^{2}}{U_{1}}}$

\section{B. IEEE Standard Definitions 1459-2010}

The standard defines the power measurement when the voltage and current are not sinusoidal, when the load is unbalanced or voltage is asymmetric and when the energy dissipated. The key concept of standard for power resolution is the separation fundamental component of voltage and current from all of harmonics component [1] and [2]. This improves the quality of measurement of instrument and traditional power monitor system. In this paper, we focus on three phase sinusoidal and non sinusoidal system. The most important definitions are summarized in Table 1.

Table 1. Lists the three basic powers: apparent, active, and nonactive. The last three rows give the following indices: harmonic pollution factor and load unbalance factor.

\begin{tabular}{|l|c|c|c|}
\hline $\begin{array}{l}\text { Quantity } \\
\text { Indicator }\end{array}$ & Combined & $\begin{array}{l}\text { Fundamental } \\
\text { Powers }\end{array}$ & $\begin{array}{l}\text { NonFundame- } \\
\text { ntal Powers }\end{array}$ \\
\hline Apparent & $\begin{array}{c}S_{e 1} S_{1}^{+} S_{1 U} \\
\text { (VA) }\end{array}$ & $\begin{array}{c}S_{e N} S_{e H} \\
\text { (VA) }\end{array}$ \\
\hline Active & $P(\mathrm{~W})$ & $P_{1}^{+}(\mathrm{W})$ & $P_{H}$ (W) \\
\hline $\begin{array}{l}\text { Non- } \\
\text { active }\end{array}$ & $N$ (var) & $Q_{1}^{+}$(var) & $D_{e I} D_{e V} D_{e H}$ \\
\hline $\begin{array}{l}\text { Line } \\
\text { Utilization }\end{array}$ & $P F=P / S_{e}$ & $P F_{1}^{+}=P_{1}^{+} / S_{1}^{+}$ & \\
\hline $\begin{array}{l}\text { Harmonic } \\
\text { pollution }\end{array}$ & - & - & $S_{e N} / S_{e 1}$ \\
\hline $\begin{array}{l}\text { Load } \\
\text { unbalance }\end{array}$ & - & $S_{1 U} / S_{1}^{+}$ & \\
\hline
\end{tabular}


The basic power component definitions [1] for three phase system we use are:

$$
\begin{aligned}
& V_{e}=\sqrt{\frac{V_{a b}^{2}+V_{b c}^{2}+V_{c a}^{2}}{9}}, \\
& V_{e l}=\sqrt{\frac{V_{a b l}^{2}+V_{b c l}^{2}+V_{c a l}^{2}}{9}} \\
& V_{e H}=\sqrt{\frac{V_{a b H}^{2}+V_{b c H}^{2}+V_{c a H}^{2}}{9}}=\sqrt{V_{e}^{2}-V_{e l}^{2}} \\
& I_{e}=\sqrt{\frac{I_{a}^{2}+I_{b}^{2}+I_{c}^{2}}{3}} \\
& I_{e 1}=\sqrt{\frac{I_{a 1}^{2}+I_{b 1}^{2}+I_{c 1}^{2}}{3}} \\
& I_{e H}=\sqrt{\frac{I_{a H}^{2}+I_{b H}^{2}+I_{c H}^{2}}{3}}=\sqrt{I_{e}^{2}-I_{e l}^{2}}
\end{aligned}
$$

The apparent power is defined as

$S_{e}=3 V_{e} I_{e}$

$S_{e 1}=3 V_{e 1} I_{e 1}$

$S_{e N}^{2}=S_{e}^{2}+S_{e l}^{2}=D_{e l}^{1}+D_{e V}^{2}+S_{e H}^{2}$

The current distortion power, voltage distortion power, and harmonic apparent power are as follows:

$$
\begin{aligned}
& D_{e l}=3 V_{e l} I_{e H} \\
& D_{e V}=3 V_{e H} I_{e l} \\
& S_{e H}=3 V_{e H} I_{e H} \\
& D_{e H}=\sqrt{S_{e H}^{2}-P_{e H}^{2}}
\end{aligned}
$$

The load unbalance can be evaluated using the following fundamental unbalanced power:

$S_{U 1}=\sqrt{S_{e l}^{2}-\left(S_{l}^{+}\right)^{2}}$

The fundamental active power

$P_{1}^{+}=3 V_{1}^{+} I_{1}^{+} \cos \theta_{1}^{+}$

The fundamental reactive power

$Q_{1}^{+}=3 V_{1}^{+} I_{1}^{+} \sin \theta_{1}^{+}$

$S_{1}^{+}=\sqrt{\left(P_{1}^{+}\right)^{2}+\left(Q_{1}^{+}\right)^{2}}$

fundamental power factor

$P F_{l}^{+}=\frac{P_{l}^{+}}{S_{l}^{+}}$

That plays the same significant role that the fundamental power factor has in nonsinusoidal single-phase systems.

The Power factor is

$P F=\frac{P}{S_{e}}$

\section{Description of the hardware}

The developed power quality monitor measurement system uses three voltage transformers $(380 \mathrm{~V}-6 \mathrm{~V})$ and 3 Hall-effect current sensors (LEM LA 55-P/SP1, 50A - 25 $\mathrm{mA}$ ) [5]. The sensors are connected to data acquisition NI USB 6211 from National Instruments through of circuit conditioning. Its main characteristics are: 16 analog inputs (16-bit, $250 \mathrm{kS} / \mathrm{s}), 2$ analog outputs (16-bit, $250 \mathrm{kS} / \mathrm{s}$ ); 4 digital inputs; 4 digital outputs; 232 - bit counters [6] [7].

A standard desktop personal computer (PC), running the Windows 7 operating system, was used as the system processing unity. Fig. 1 shows a block diagram of the developed power quality monitoring system.

The signals of voltage and current are converted to the signals applicable for the data acquisition card through voltage and current transformers, then, through the signal conditioner, these signals are conditioned to be sent to the data acquisition card by were subsequently analyzed.

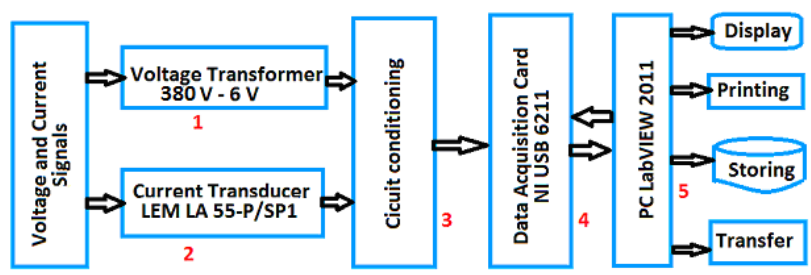

Fig. 1. Shown block diagram of developed instrument.

\section{Software.}

This section describes briefly the programming environment used for creating the measurement system. LabVIEW is a platform and development environment for a visual programming language from National Instruments. It is a graphical language designed for engineers and scientists and quite unique in the method by which code is constructed and saved [8].

The LabView environment contains pre-installed drivers for a variety of measurement devices. The configuration of devices is in most cases done without user help.

In this software user is able to choose and synchronize used hardware and create measurement tasks. A task is a predefined configuration setting for a specific device. The settings can also be passed to the device directly from a VI. In our case we preferred to set up a task. Fig. 3. illustrates a basic LabVIEW structure used to implement continuous acquisition [9].

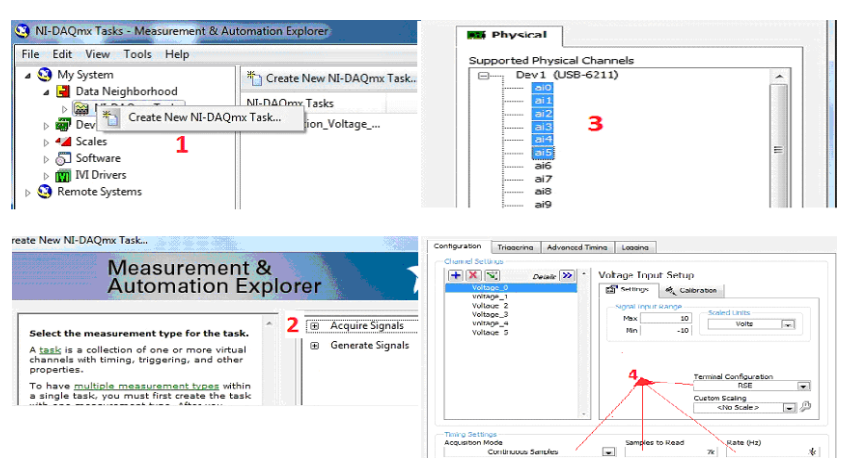

Fig. 2. Process task settings.

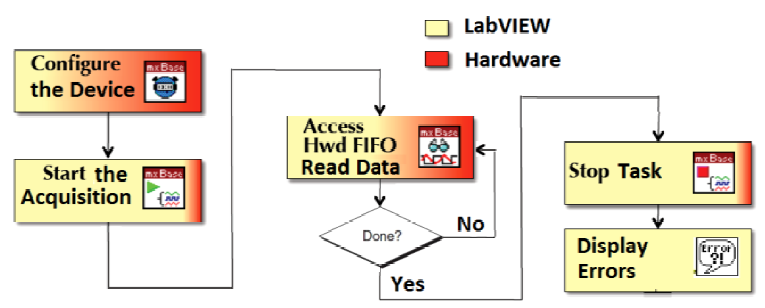

Fig. 3. The Flowchart of Continuous Acquisition. 


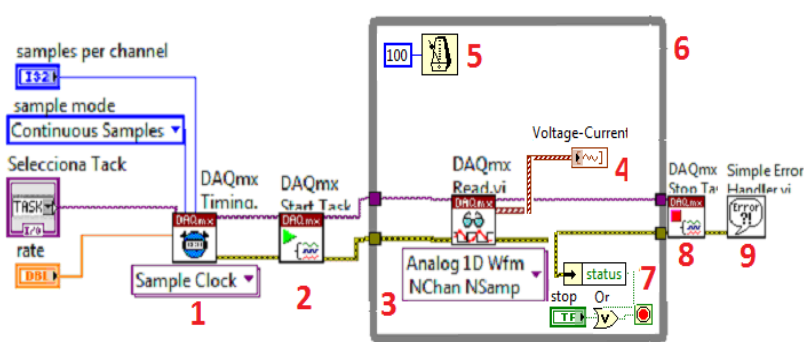

Fig. 4. Block diagram of a continuous buffered acquisition.

(1) This "VI DAQmx Timing" configures the sample timing and buffer size (samples per channel) of the task. Select the Sample Clock instance from the pull-down menu to use the internal clock on the DAQ device. (2) This " $V I$ DAQmx starts" the measurement task. (3) This VI "DAQmx Read" Reads a certain number of samples from the circular buffer (it is inside a While cycle, which ends only when the program is terminated). (5) The Wait Until Next ms Multiple function on the block diagram. This function causes the loop to execute every $100 \mathrm{~ms}$. (6) Place a While Loop on the block diagram. The While Loop repeats the subdiagram inside it until the conditional terminal receives a particular Boolean value. (8) This "VI stops" the measurement task. The task can be started again (9) In the event of an "error", this VI displays a dialog box with information regarding the error and its location [9].

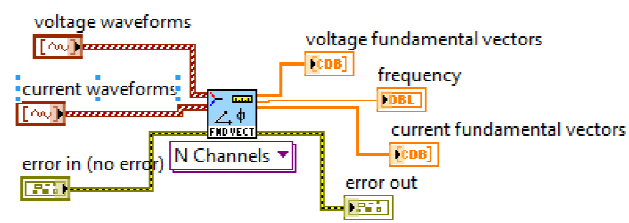

Fig. 5. Fundamental Vector.VI: Calculates the fundamental vector of a voltage or current signal for $\mathrm{N}$ channels.

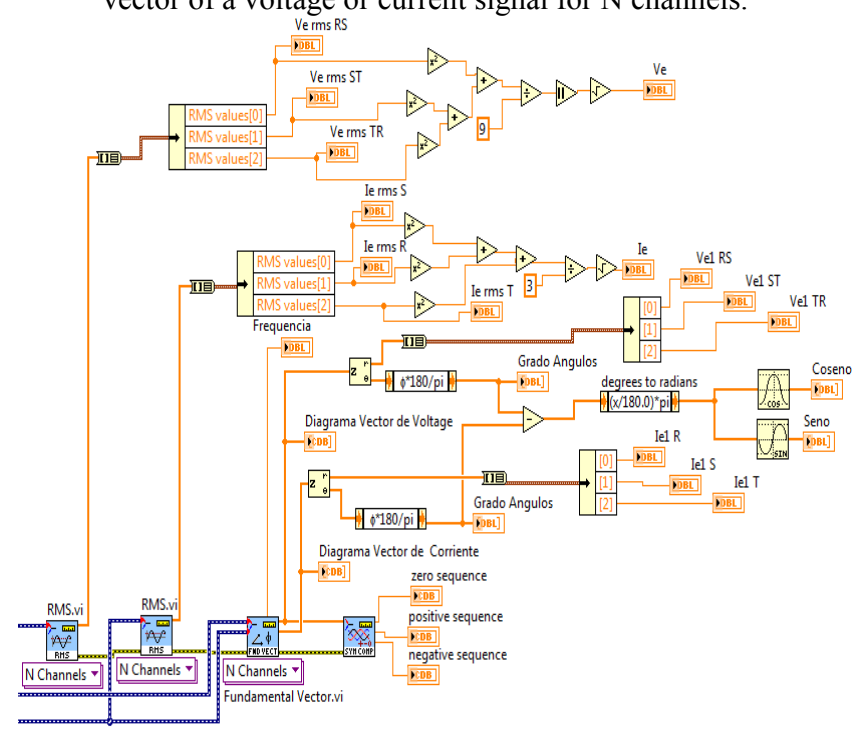

Fig. 6. Corresponding block diagram for the voltage and current RMS and Fundamental vector.

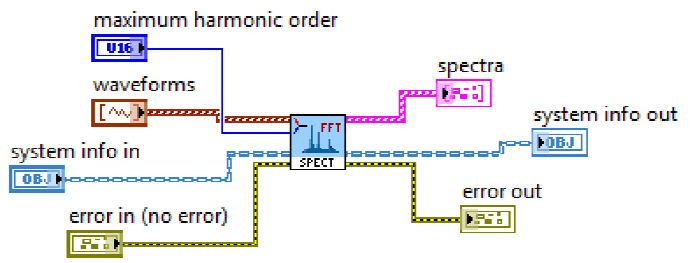

Fig. 7. Spectrum of the distorted using FFT.
FFT spectra VI: Computes the FFT spectra of input waveforms. This VI returns FFT spectra as complex spectra of voltage and/or current, up to a specified maximum harmonic order with a frequency resolution around $5 \mathrm{~Hz}$, which is the fundamental frequency divided by 10 or 12 .

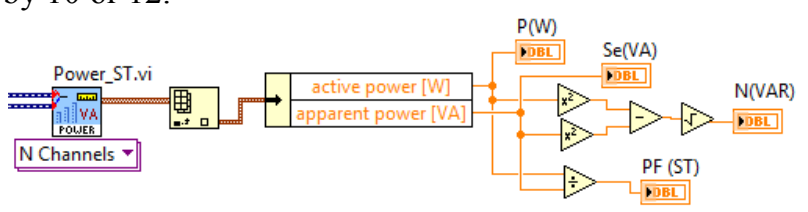

Fig. 8. Determination of electric powers.

Power VI: Calculates power values from voltage and current spectra. This VI returns apparent power, active power, reactive power, and the power factor.

Storage of measurement data, the data can be stored in different ways, as for example in a database or in a dedicated file. Creation of a dedicated database would be time consuming and was not a part of specifications for the thesis. It was therefore decided to store data in a set of files, according to the aggregation times. Write To Measurement File Express VI.

\section{Experimental Results}

The virtual instrument developed through the front panel, graphical user interface (GUI) provides analysis functions according to the standard EN 50160: Magnitude of the supply voltage and Current, frequency, the phasors diagrams for voltage and current [10], Voltage and Current harmonics, voltage unbalance. And other analysis conforms to the IEEE Standard 1459-2010: real and reactive power, energy use, power factor and frequency etc [1] and [2].

The system was tested and calibrated in laboratory provides continuous monitoring of a three-phase system, with resistive, inductive and capacitive loads.

Figs. 9, 10, 15, 19 shows the front panel the experimental results, in case of a sinusoidal, balanced and unbalanced three-phase system with fundamental line-to-line voltage of $380 \mathrm{~V}$. The rms effective voltage (Ve), the fundamental voltage (Ve1) the nonfundamental $\mathrm{VeH}$ and the rms effective current (Ie), the fundamental current (Ie1) the nonfundamental (IeH). The current distortion power (DeI), voltage distortion power $(\mathrm{DeV})$, the total harmonic distortions (THDeV, THDeI). The phasors diagrams for voltage and current, the fundamental frequency. The phase angle between the phasors, and the cosine and sine. The Fig 9. shows the result of the test with unbalanced resistiveinductive load. The Fig. 10. shows the result of the test with distorted and balanced resistive load. Where we note that the harmonic factor is very high due to the great value of THDeI in the load current. And the presence of 0 representing the harmonic current DC. (Figs. 13 and 14).

Figs. 15 and 19 presents the results in case of a sinusoidal and balanced three-phase system with fundamental line-to-line voltage of $380 \mathrm{~V}$, where Fig. 15. is connected to three phase transformer a load without and Fig. 19. inductive load.

Figs. 11, 12, 16, 20 Shown the results the developing Harmonic Power Analyzer based on IEEE 1459-2010 Standard for three phases power system [1]. 


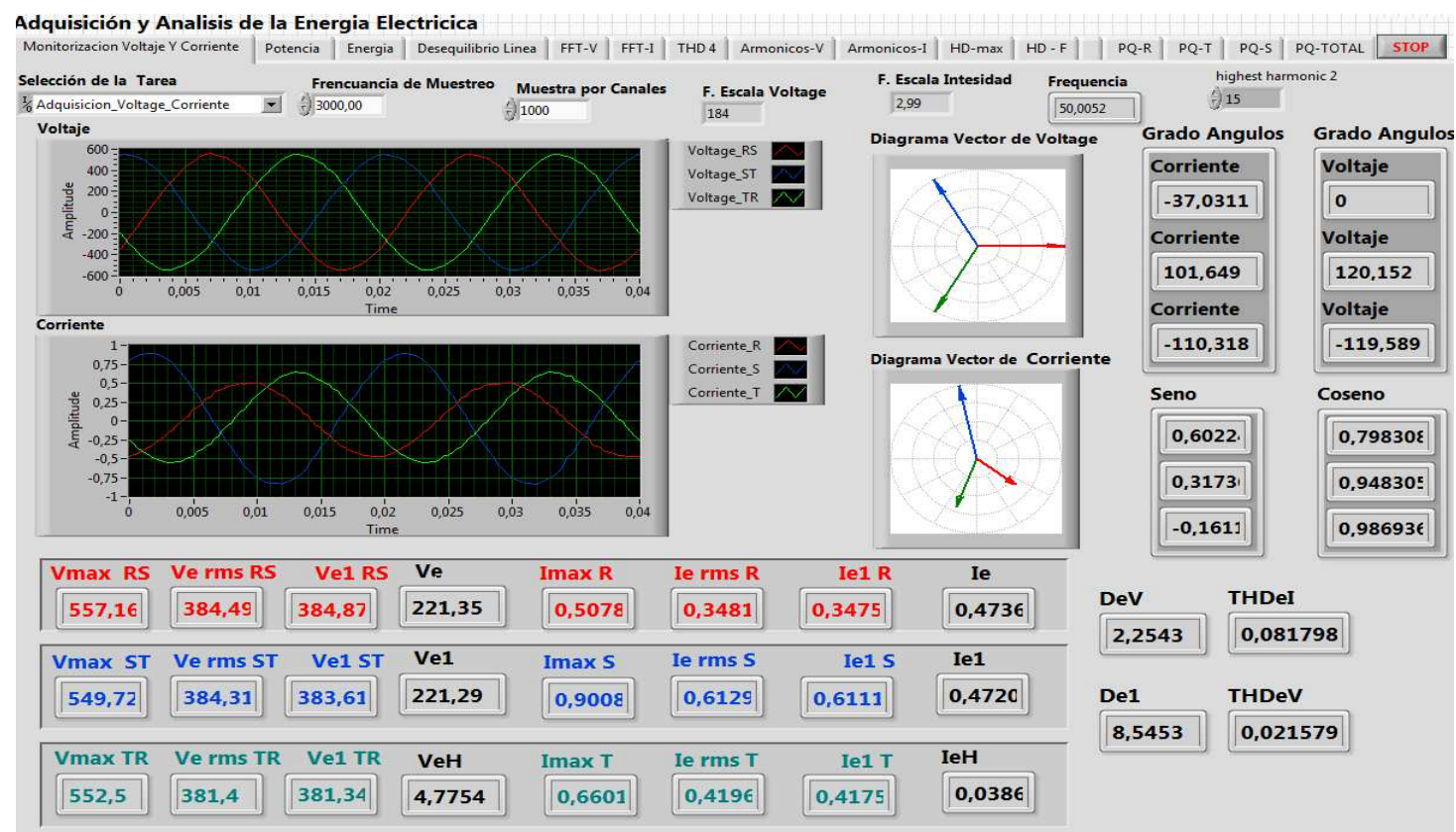

Fig. 9. Experimental test under a sinusoidal three-phase system with unbalanced resistive inductive load.

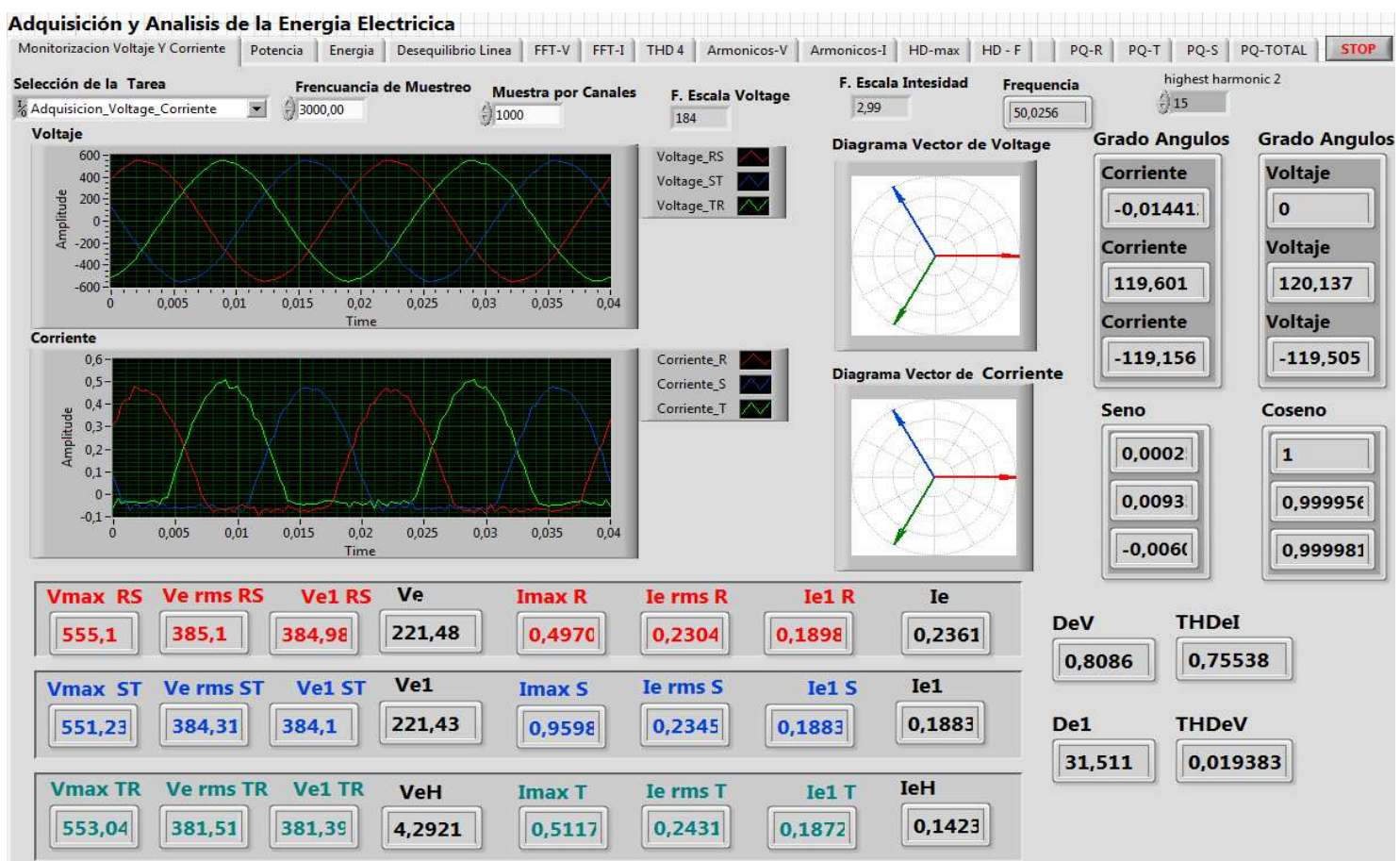

Fig. 10. Experimental test under a sinusoidal and balanced three-phase system with distorted and balanced resistive load.

Adquisición y Analisis de la Energia Electricica

\begin{tabular}{|c|c|c|c|c|c|c|c|c|c|}
\hline \multirow{3}{*}{$\begin{array}{l}\text { Quantity or indicator } \\
\text { Apparent (VA) }\end{array}$} & \multicolumn{2}{|c|}{ Combined } & \multicolumn{3}{|c|}{ Fundemental Powers } & \multicolumn{4}{|c|}{ Nonfundemental Powers } \\
\hline & \multirow[b]{2}{*}{ Se } & \multirow[b]{2}{*}{314,523} & Se1 & $51+$ & S10 & \multirow[b]{2}{*}{ SeN 0} & \multirow[b]{2}{*}{0,084615} & \multirow[b]{2}{*}{ SeH } & \multirow[b]{2}{*}{0,1844} \\
\hline & & & 313,403 & 276,745 & 147,083 & & & & \\
\hline Active (W) & $\mathbf{P}$ & 281,219 & $\mathrm{P} 1+$ & 271,449 & & PeH & 9,4919 & & \\
\hline & & & & & & De1 & $\mathrm{DeV}$ & & DeH \\
\hline Non-Active (var) & $\mathrm{N}$ & 140,855 & Q1+ & 53,8805 & & 8,5453 & 2,2 & 543 & 9,4901 \\
\hline Line Utilization & PF & 0,894 & PF1+ & 0.981 & & & & - & \\
\hline Harmonics Pollution & $\ldots$ & - & & - & & $\mathrm{SeN} / \mathrm{Se}$ & & 0,0002 & \\
\hline Load Unbalance & & {[} & $\mathrm{S} 1 \mathrm{U} / \mathrm{S} 1+=$ & $=0,531$ & & & & - & \\
\hline
\end{tabular}

Fig. 11. Experimental test under a sinusoidal and balanced threephase system with unbalanced resistive inductive load (Fig. 9).
Adquisición y Analisis de la Energia Electricica

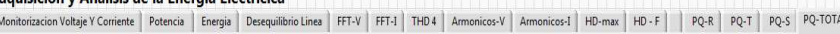

\begin{tabular}{|c|c|c|c|c|c|c|c|c|}
\hline Quantity or indicator & Com & bined & & ndemental P & & NonFunde & iental P & owers \\
\hline & & & Se1 & $51+$ & S10 & & & \\
\hline Apparent (VA) & Se & 156,869 & 125,147 & $\mid 125,145$ & 0,83222 & SeN 0,75577 & SeH & 0,6108 \\
\hline Active (W) & P & 125,546 & & 125,145 & & PeH 0,5 & & \\
\hline & & & & & & De1 & & DeH \\
\hline Non-Active (var) & $\mathrm{N}$ & 94,0534 & Q1 & - 0,141767 & & 31,511 & 8086 & 0,2631 \\
\hline Line Utilization & PF & 0,8 & PF1 & +1 & & & & \\
\hline Harmonics Pollution & & - & & $\square$ & & SeN/Se1 = & 0,006 & \\
\hline Load Unbalance & & 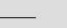 & $S 10 / 51$ & $=0,00665$ & & & & \\
\hline
\end{tabular}

Fig. 12. Experimental test under a sinusoidal and balanced, threesystem with distorted and balanced resistive load (Fig. 10). 


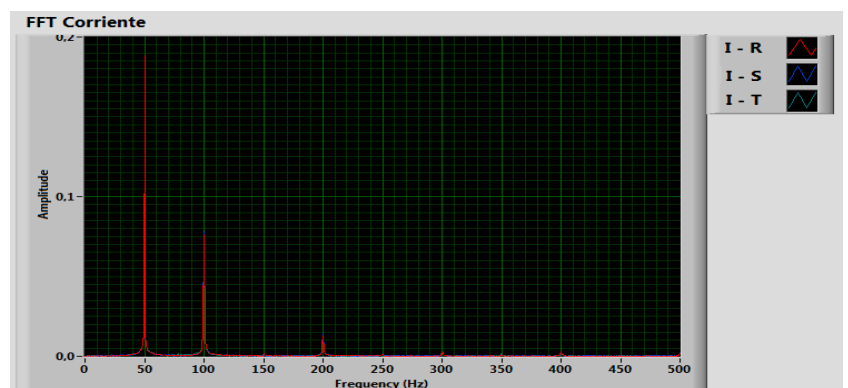

Fig. 13. FFT result for inputs the figure 10.

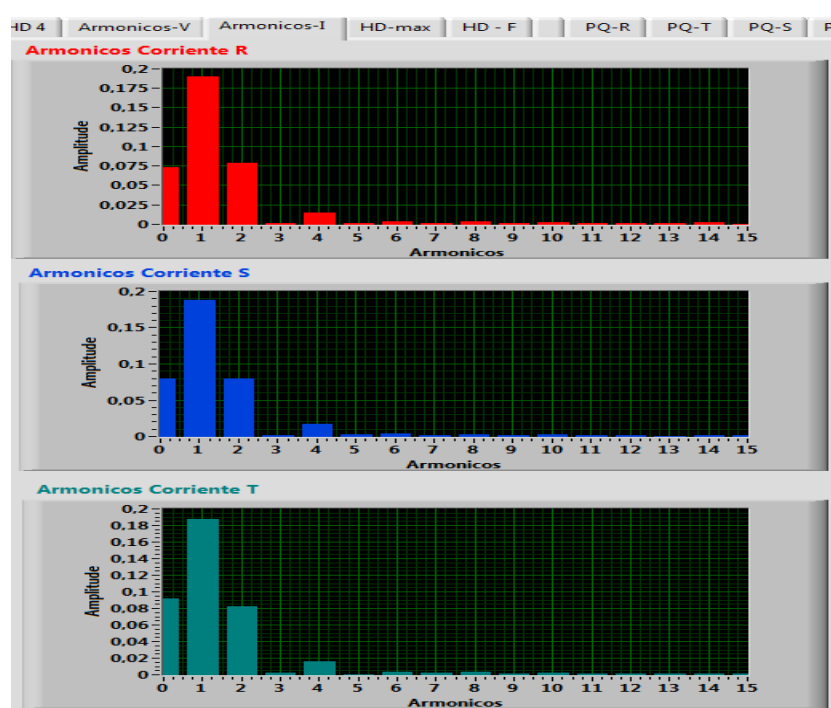

Fig. 14. Spectral harmonics analysis for inputs current the Fig. 10.

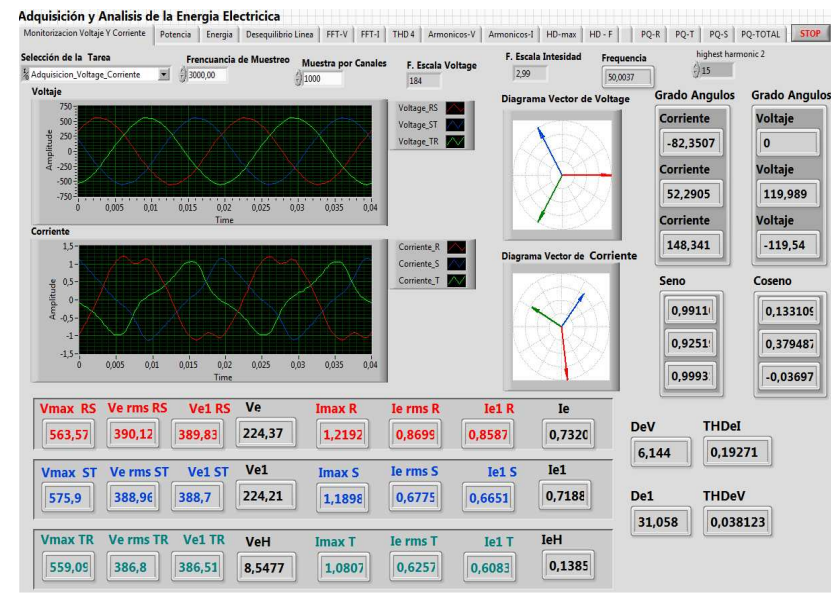

Fig. 15. Experimental test under a sinusoidal and balanced threephase system connected to three phase transformer a load without.

\begin{tabular}{|c|c|c|c|c|c|c|c|}
\hline \multirow{3}{*}{$\begin{array}{l}\text { Quantity or indicator } \\
\text { Apparent (VA) }\end{array}$} & Combined & \multicolumn{3}{|c|}{ Fundemental Powers } & \multicolumn{3}{|c|}{ NonFundemental Powers } \\
\hline & & Se1 & $51+$ & 510 & & & \\
\hline & Se 492,741 & 483,487 & 470,731 & 110,326 & SeN 0,19659 & SeH & 1,184 \\
\hline Active (W) & $\begin{array}{ll}\text { P } 78,3818 \\
\end{array}$ & & 64,2416 & & PeH 14,3 & & \\
\hline & & & & & De1 & Dev & DeH \\
\hline Non-Active (var) & N 486,467 & Q1 & 466,327 & & 31,058 & 6,144 & 14,271 \\
\hline Line Utilization & $\begin{array}{lll}\text { PF } & 0,159\end{array}$ & PF1 & 0,136 & & & 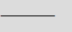 & \\
\hline Harmonics Pollution & - & & 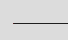 & & $\mathrm{SeN} / \mathrm{Se} 1=$ & 0,0004 & \\
\hline Load Unbalance & - & $s 10 / s 1$ & $=0.234$ & & & - & \\
\hline
\end{tabular}

Fig. 16. Experimental test under a sinusoidal and balanced threephase system connected to three phase transformer a load without, for inputs the Fig. 15

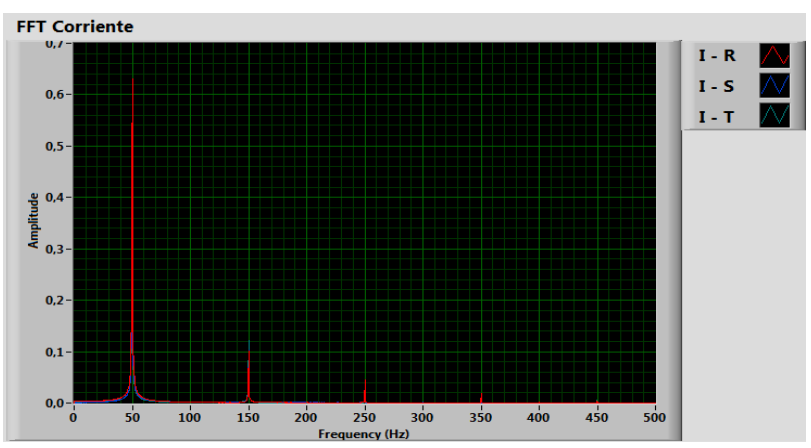

Fig. 17. FFT result for inputs current the figure 15.

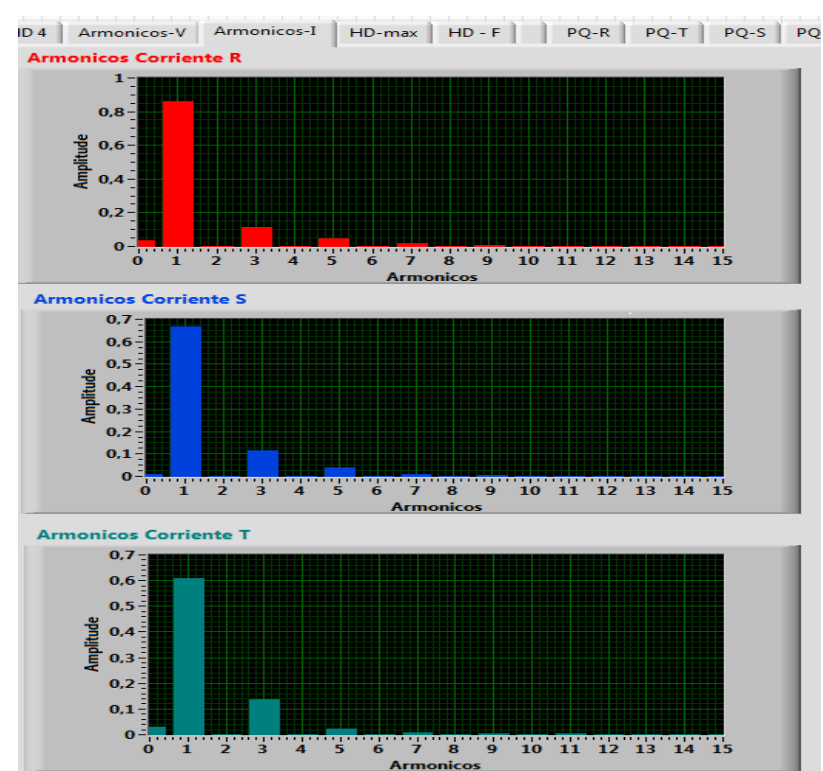

Fig. 18. Spectral harmonics analysis for inputs current of the Fig. 15.

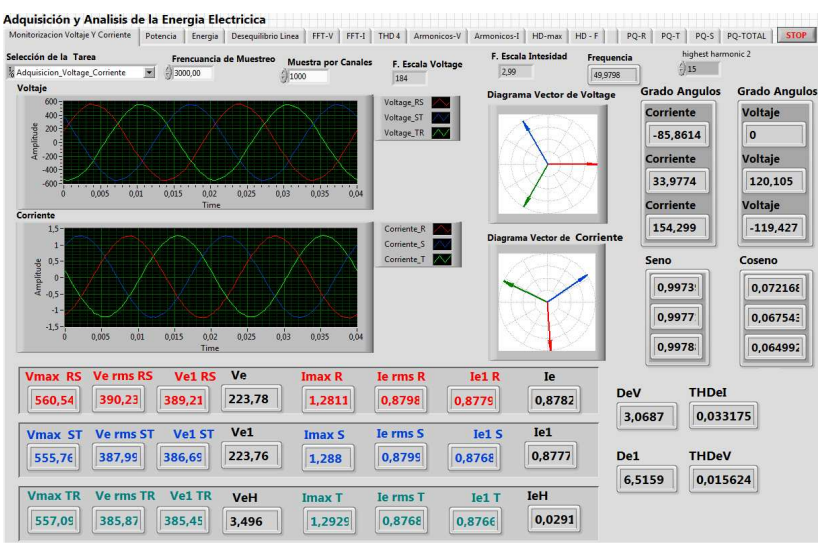

Fig 19. Three phases measurement window display inductive load.

\begin{tabular}{|c|c|c|c|c|c|c|c|c|}
\hline \multirow{2}{*}{$\begin{array}{l}\text { Quantity or indicator } \\
\text { Apparent (VA) }\end{array}$} & \multicolumn{2}{|c|}{ Combined } & \multicolumn{3}{|c|}{ Fundemental Powers } & \multicolumn{3}{|c|}{ Nonfundemental Powers } \\
\hline & & 589,62 & \begin{tabular}{|l|} 
Se1 \\
589,224
\end{tabular} & $\begin{array}{l}\text { S1+ } \\
589,218\end{array}$ & \begin{tabular}{|c|} 
S1U \\
2,6125
\end{tabular} & SeN 0.0366 & $74 \mathrm{SeH}$ & 0,10181 \\
\hline Active (W) & $\mathbf{P}$ & 40,4384 & P1+ & 40,2022 & & $\begin{array}{lll}\text { PeH } & 0,1 & \end{array}$ & 6626 & \\
\hline Non-Active (var) & $\mathrm{N}$ & 588.232 & Q1+ & 587,845 & & \begin{tabular}{|l|} 
De1 \\
6,5159 \\
\end{tabular} & $\begin{array}{l}\text { ev } \\
3,0687\end{array}$ & $\begin{array}{l}\text { DeH } \\
0,1314\end{array}$ \\
\hline Line Utilization & PF & 0,0686 & PF1 & $+0,0682$ & & & - & \\
\hline Harmonics Pollution & - & - & & 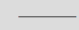 & & SeN $/$ Se1 $=$ & 6,2E-5 & \\
\hline Load Unbalance & & - & s1u/s1+ & $=0,00443$ & & & ـ & \\
\hline
\end{tabular}

Fig. 20. Experimental test under a sinusoidal and balanced three-phase system with inductive balanced load, for inputs on Fig. 19. 


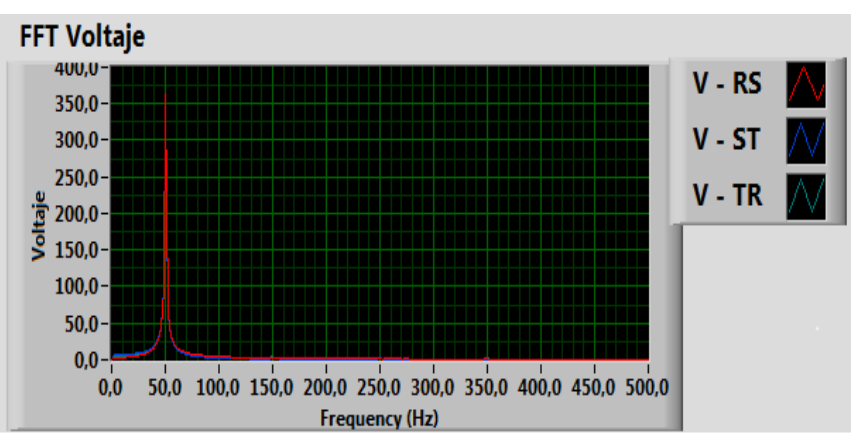

Fig. 21. FFT result for inputs voltage the Fig. 19.

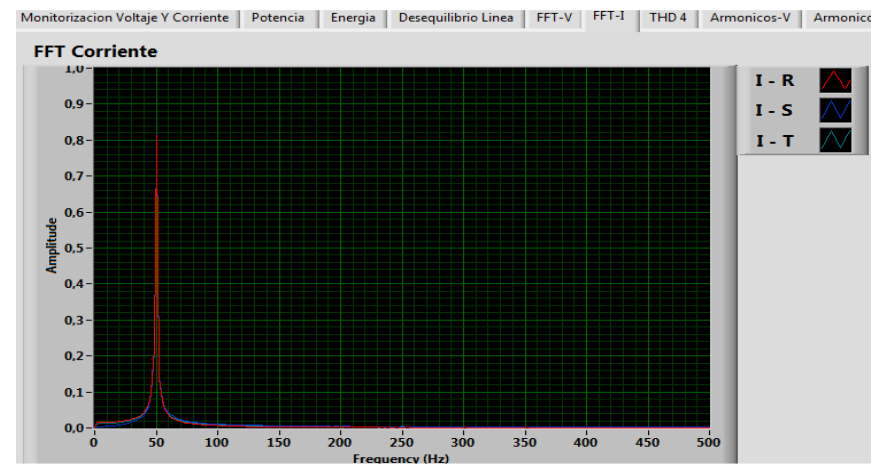

Fig. 22. FFT result for inputs current the figure 19.

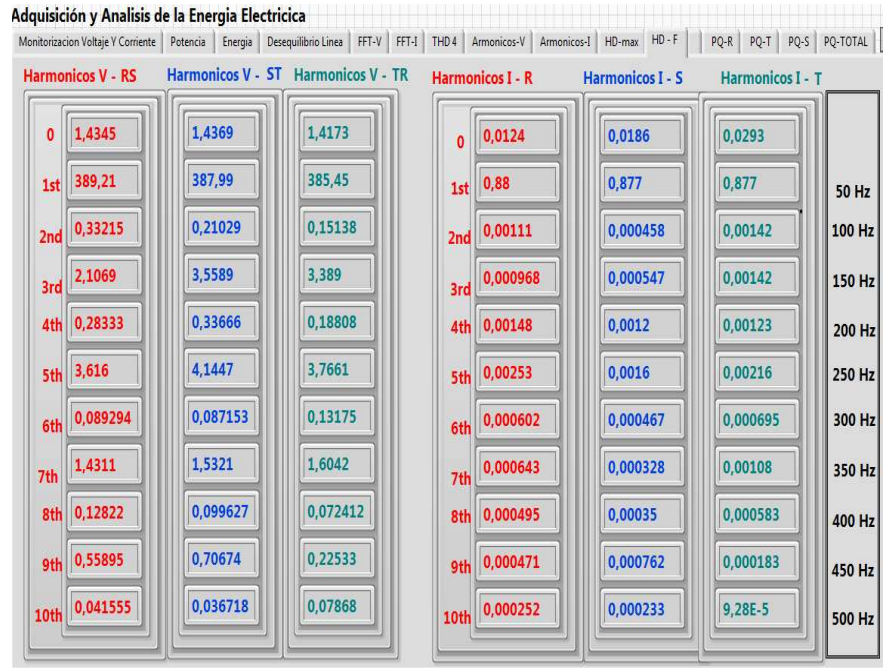

Fig. 23. Harmonic calculation for inputs fundamental voltage and current the Fig. 19.

\section{Conclusion}

\section{A. Summary of findings}

This paper describes a developed system that can be very useful for power management and power quality monitoring, suitable for industrial or commercial facilities, or even for research purposes. To accomplish that, transformers de voltage and hall effect sensors current, the National Instruments USB6211 is a bus-powered USB M Series multifunction data acquisition (DAQ), a LabView environment, as it provides a programming language with possibilities of easy control of external hardware and of being used in many hardware and software platforms, as FPGA, PDA (personal digital assistant) and PC (personal computers) with a variety of operating systems. The system has been used to perform measurements at tension, current, frequency, to calculate powers, harmonics according to the EN 50160 and IEEE Standard 1459-2010, which is documented by section 5 .
The developed monitoring system is flexible, presents a user-friendly interface and a large data storage capacity, since it uses the PC hard disk for that purpose. It generates HTML reports that can be accessed through Internet, and can also generate data for other applications running in the Windows environment.

\section{B. Implications for the future.}

The further development of the created system, by: Addition of modules responsible for control of current or voltage overload. Adding a possibility of storing data in a data base, adding a possibility of controlling the communicating with the system over the Internet, using CompactRIO.

\section{References}

[1] IEEE Std. 1459 (2010). IEEE Standard Definitions for the Measurement of Electric Power Quantities under Sinusoidal, Nonsinusoidal, Balanced, or Unbalanced Conditions, March 2010, ISSN 978-0-7381-6058-0, New York, USA.

[2] A. E. Emanuel, "Summary of IEEE standard 1459: definitions for the measurement of electric power quantities under sinusoidal, nonsinusoidal, balanced or unbalanced conditions," IEEE Trans. Ind. Appl., Vol. 40, no. 3, pp. 869876, May/Jun. 2004.

[3] UNE-EN 50160, "Características de la tensión suministrada por las redes generales de distribución”, Norma Española AENOR Abril 2008. Madrid.

[4] Henryk Markiewicz \& Antoni Klajn, Voltage Disturbances Standard EN 50160 - Voltage Characteristics in Public Distribution Systems. Wroclaw University of Technology CEDIC, Julio 2004.

[5] Caracteristics Transductor de corriente LA55-P/SP1,50A. http://es.rs-online.com/web/p/transductores-decorriente/1807391/, accessed August 29, 2012

[6] NI USB 6211, specification.

http://sine.ni.com/nips/cds/view/p/lang/en/nid/203224, accessed september 5, 2012

[7] DAQ M Series, NI USB-621x User Manual, USA, April 2009.

[8] J. Barros, M. de Apraiz, R.I. Diego, "A virtual measurement instrument for electrical power quality analysis using wavelets", Measurement, No.42, pp.298-307, 2009.

[9] NI. "Data Acquisition and Signal Conditioning Course Manual", Course Software Version 8.0, October 2005 Edition, USA, Part Number 320733L-01.

[10] N. Ertugrul, LabVIEW for Electric Circuits, Machines, Drives and Laboratories Prentice Hall., USA, ISBN: 0-13061886-1, 436 pages, 2002. 